Portland State University

PDXScholar

1982

\title{
Extraversion-introversion and sensitivity to nonverbal cues
}

Virginia Seiser

Portland State University

Follow this and additional works at: https://pdxscholar.library.pdx.edu/open_access_etds

Part of the Personality and Social Contexts Commons, and the Social Psychology Commons Let us know how access to this document benefits you.

\section{Recommended Citation}

Seiser, Virginia, "Extraversion-introversion and sensitivity to nonverbal cues" (1982). Dissertations and Theses. Paper 3220.

https://doi.org/10.15760/etd.3211

This Thesis is brought to you for free and open access. It has been accepted for inclusion in Dissertations and Theses by an authorized administrator of PDXScholar. Please contact us if we can make this document more accessible: pdxscholar@pdx.edu. 
AN ABSTRACT OF THE THESIS OF Virginia Seiser for the Master of Science in Psychology presented July, 1982.

Title: Extraversion-Introversion and Sensitivity in Nonverbal Cues APPROVED BY MEMBERS OF THE THESIS COMMITTEE:

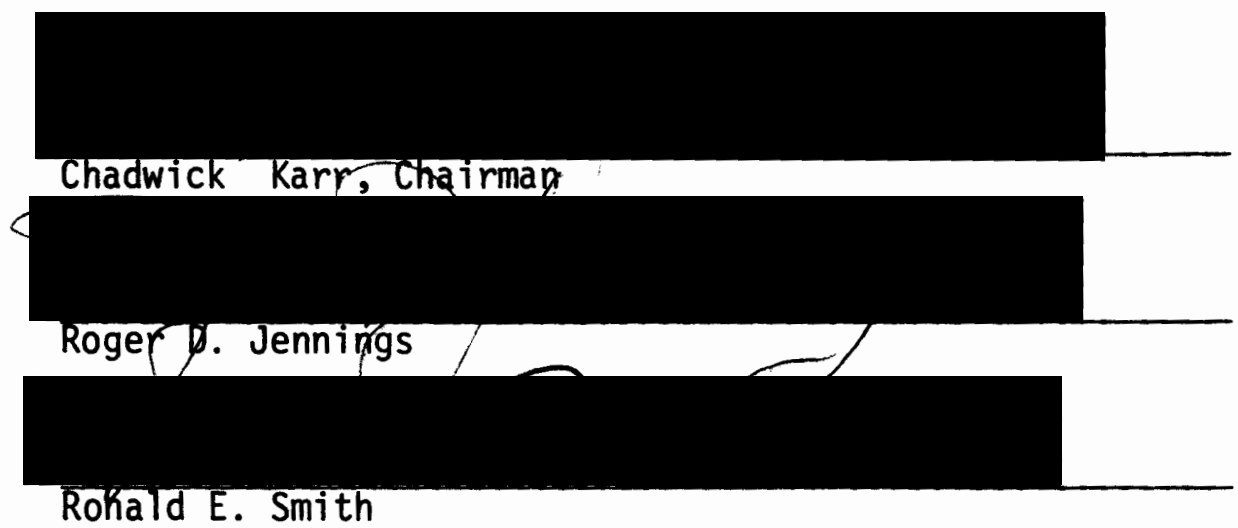

Sixty-five college students completed the Profile of Nonverbal Sensitivity (PONS) and the Eysenck Personality Questionnaire. The results did not support the hypothes is that introverts would be found to be relatively more sensitive to negative nonverbal cues than to positive cues, and that this difference would be greater for introverts than for extraverts. The outcome did not support predictions concerning the relationship between sensitivity to nonverbal communication and extraversion-introversion based on either Gray's fear-frustration hypothes is or Eysenck's general conditionability hypothesis of extraversion-introversion.

The results supported findings of earlier researchers that females are more sensitive to nonverbal cues than males, and that both sexes 
are somewhat more sensitive to negative cues than positive cues. Males were less accurate and more variable than females in their responses to the PONS. Response bias was found to be a small but statistically significant influence on PONS test results. 


\title{
EXTRAVERSION-INTROVERSION AND SENSITIVITY
}

TO NONVERBAL CUES

\author{
by \\ VIRGINIA SEISER
}

A thesis submitted in partial fulfillment of the requirements for the degree of

\author{
MASTER OF SCIENCE \\ in \\ PSYCHOLOGY
}

Portland State University

1982 
TO THE OFFICE OF GRADUATE STUDIES AND RESEARCH:

The members of the Committee approve the thesis of Virginia Seiser presented JuTy, 1982.

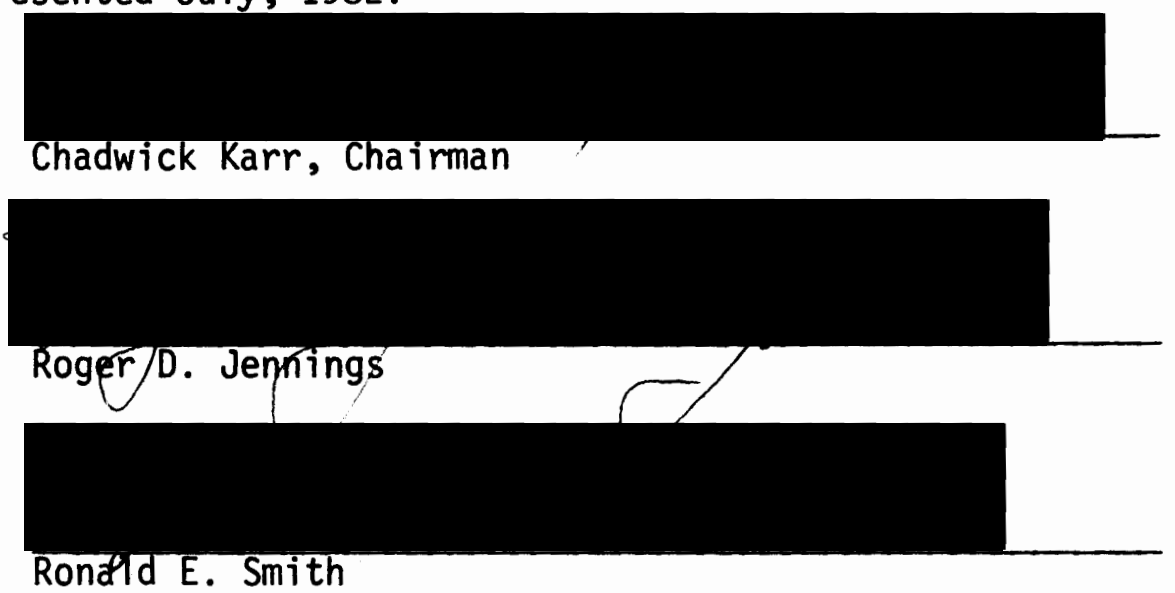

APPROVED:
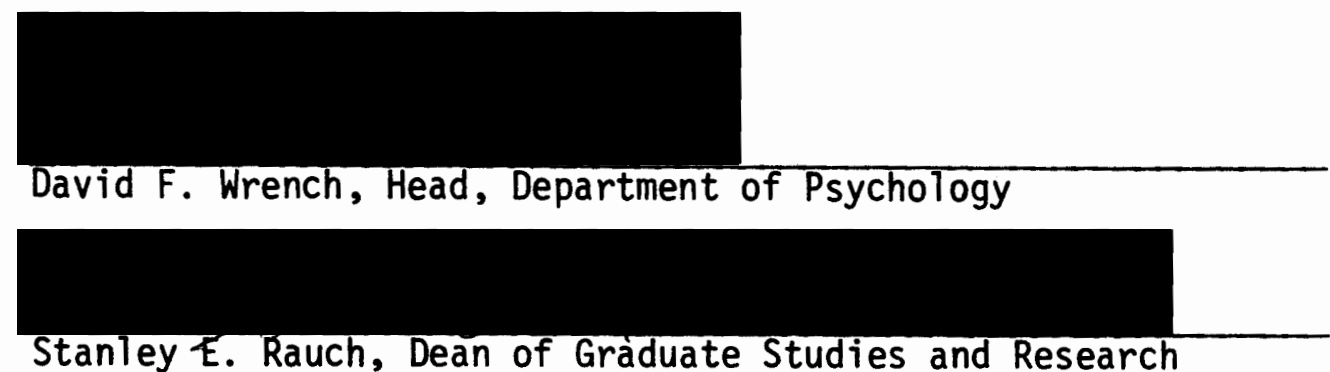

Stanley E. Rauch, Dean of Graduate Studies and Research 


\section{ACKNOWLEDGEMENTS}

I would like to thank my thes is committee, Chadwick Karr, Roger Jennings and Ronald Smith, for their advice and guidance. In particular, I wish to express my appreciation to Chad Karr for his encouragement, patience, and unfailing good humor. I am grateful to Barry Anderson for suggestions concerning the response bias issue, and to Frank Wesley and David Wrench, for allowing me to present my study to their classes. I would also like to thank the 88 anonymous undergraduates who participated in my study.

My research was made possible, in part, by a sabbatical leave granted to me by the Portland State University Library. My thanks to colleagues there who took on added responsibilities in my absence, including Kathleen Greey, Kathy Dusky, Rebecca Reed, and Elaine Heras.

Finally, I wish to express my appreciation to the many friends and colleagues who listened, made suggestions, and offered encouragement throughout the process of completing this project. 
TABLE OF CONTENTS

PAGE

ACKNOWLEDGEMENTS ............................. . . . . . . . .

LIST OF TABLES . . . . . . . . . . . . . . . . . . . vi

LIST OF FIGURES . . . . . . . . . . . . . . . . vii

SECTION

I INTRODUCTION ........................ 1

II REVIEW OF THE LITERATURE . . . . . . . . . . . 4

Decoding Studies Employing Measures of

Extraversion-Introversion ........... 4

Extraversion-Introversion and the Fear-

Frustration Hypothesis ........... 10

Purpose of this Study ............. . 14

III METHODS .................. 16

Subjects ................ 16

Procedure ............... 16

Instruments . . . . . . . . . . . . . 17

Eysenck Personality Questionnaire . . . . . . 17

Profile of Nonverbal Sensitivity . . . . . . 18

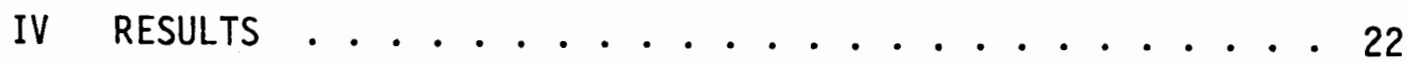

Extraversion-Introversion .......... . 22

Nonverbal Sensitivity . . . . . . . . . 23

Response Bias ............... . . 26 
PAGE

SECTION

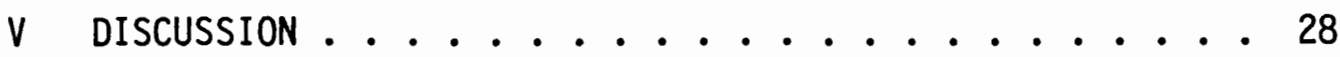

Conclusion ................. 29

Implications for Further Research . . . . . . 29

REFERENCE NOTE ........................... 31

REFERENCE LIST .................. . . 32

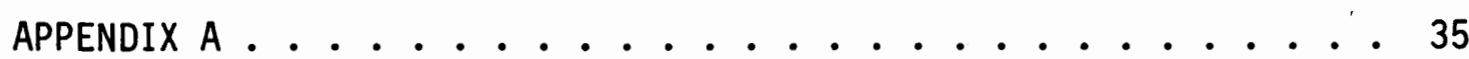

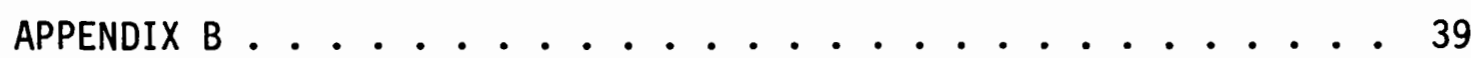




\section{LIST OF TABLES}

TABLE

PAGE

I Classification of the 20 PONS scenes on the dimensions

of positivity and dominance......... 19

II The eleven PONS channels . . . . . . . . . . . . 19

III Distribution of the 220 PONS segments among the twenty scenes and eleven channels ......... . 20

IV Scores on the Eysenck Personality Inventory

E Scale............... 23

$\checkmark$ Total Scores on the Profile of Nonverbal

Sensitivity............. . . 23

VI Positive and Negative Subscores on the Profile of

Nonverbal Sensitivity .......... . 24

VII Analysis of Variance on Three Factors: Extraversion-

Introversion, Sex, PONSt ......... 25

VIII Correlation between E Score and PONS ......... 26 


\section{LIST OF FIGURES}

FIGURE

PAGE

1. Rank Ordering of Group Means for Profile of Nonverbal Sensitivity Scores . . . . . . . . . . 26 


\section{SECTION I}

\section{INTRODUCTION}

Proposed definitions of nonverbal communication have ranged from the very broad, in which all human responses other than speech or writing are included, to the very specific, such as that of Wiener, Devoe, Rubinow, and Geller (1972). They state that nonverbal communication "implies (a) a socially shared signal system, that is a code, (b) an encoder who makes something public via the code, and (c) a decoder who responds systematically to that code" (p. 186). In their extensive review of nonverbal communication research, Harper, Wiens, and Matarazzo (1978) argue for the superiority of this latter approach (pp. 2-3).

Duncan (1969) identifies two major trends in research in nonverbal communication, the structural approach and the external variable approach. In the first, the structuralist approaches nonverbal communication in the same way a linguist does verbal behavior, seeking underlying units and internal rules of communication. The method relies heavily on observational rather than experimental data. In the second, the researcher seeks systematic relationships among variables, focusing on the relation between nonverbal behavior and the psychological state of the sender, or between nonverbal behavior and the perception of meaning by sender and receiver.

Rosenthal states that his work represents a third trend in nonverbal research, the individual differences approach (Rosenthal, Ha11, DiMatteo, Rogers, \& Archer, 1979, pp. 2-3). In this approach, the 
researcher focuses on differences among individuals, and secondarity, on regularities across groups. The approach examines both the nonverbal style and the communication skill of the sender, and the decoding skill and channel preferences of the receiver of the communication.

Harper et al. (1978) note that the initial phase of modern research on nonverbal behavior "involved primarily the development of transcription systems for categorizing nonverbal behaviors"(p. 13). Nonverbal communication is complex, both in terms of the content and the medium. Nonverbal communication can utilize a number of channels simultaneously. Visual components include facial expression, eye movement, and other kinesic behavior, such as posture, carriage, and gesture. Audio information includes voice qualities such as pitch, tempo, and loudness during speech, as well as nonlanguage sounds. Modern research is greatly facilitated by the existence of motion picture, video, and sound recording technology capable of capturing much of the complexity of these fleeting phenomena. Communication can also take place in tactile and olfactory channels (Morris \& Udry, 1978), but they have not been a major area of research interest.

As for trends in nonverbal research, Harper et a1. (1978) predict:

In addition to the issue of multichannel communication there are some other areas of nonverbal research...that are emerging as important. Specifically, the "encoding" and "decoding" of nonverbal behaviors... will become a major area of interest to students of nonverbal communication.... (p. 319)

They specifically point to the work of Rosenthal and his associates at Harvard, which has been in progress since 1971. The study of encodingdecoding is not new, however. It can be traced back to Charles Darwin's (1873) research on facial expression. Rosenthal's interest in how the receiver decodes nonverbal cues grew out of his work on expectancy effects, 
in which experimenters' expectations of subjects' responses were shown to influence experimental outcomes (Friedman, 1979, p. 18). To investigate decoding skill, Rosentha1, Ha11, Archer, DiMatteo, and Rogers (1979) found it necessary to deveiop a standardized, validated instrument to measure individual accuracy in interpreting multichannel nonverbal cues. The resulting instrument, the Profile of Nonverbal Sensitivity (PONS), is described in the methodology section below.

Howard Friedman (1979) sees important implications for psychology in encoding-decoding studies. Encoding-decoding research directs attention to the skill aspect of social communication, which "allows a scientific and quantitative approach to the subtle feelings expressed and detected in interpersonal relations" (p. 3). The focus on expression and detection of nonverbal cues by social interactants is a shift in orientation "away from motives and traits and toward abilities as explanatory constructs in analyzing social behavior" (p. 3). Friedman anticipates that correlations will be found between nonverbal skills and personality traits (p. 13), and sees the interest in individual differences in nonverbal skill as potentially bringing together researchers in the fields of personality and social psychology. 


\section{SECTION II}

\section{REVIEW OF THE LITERATURE}

In his discussion of nonverbal skill and the study of personality traits, Friedman (1979) notes "there is increasing evidence that extraversion is related to a number of nonverbal skills" (p. 13). Buck (1979) has reviewed the research which indicates a positive relationship between extraversion and nonverbal sending ability (pp. 141-143). My review focuses on studies which attempt to correlate extraversion-introversion and skill in decoding nonverbal cues.

\section{DECODING STUDIES EMPLOYING MEASURES OF EXTRAVERSION-INTROVERSION}

Argyle, Salter, Nicholson, Williams, and Burgess (1969) took an approach somewhat like that which Rosenthal and his associates were to use. Argyle and his colleagues showed their subjects videotapes of a sender enacting brief, prepared scenes, some with verbalization, some not. In each scene, the sender portrayed inferiority, superiority, or neutrality. Argyle et a1. hypothesized that introverts would be more sensitive to nonverbal than to verbal signals. However, they did not report any correlation between subjects' ratings of the scenes and their extraversion scores on the Maudsley Personality Inventory.

Ellgring (1970) and von Cranach (1971), pursuing an interest in eye contact, also termed "mutual looking," reported research on accuracy of judgments of direction of the sender's glance. They found certain 
correlations between accuracy and the receiver's score on the Brengelmanns' Fragenbögen der Extraversion [Inventory of Extraversion]. Von Cranach (1971) found that under some experimental conditions, extraverts were more accurate than other subjects; under other conditions, less accurate. For example, when the receiver was to judge which of seven points on his/her face was fixated by a sender of looking signals, under two different conditions of distance between receiver and sender, receivers who were extraverts judged less accurately than introverts at the greater distance. However, when the sender was instructed to vary head position as well as point of fixation, it was found that extraverts judged gaze direction more accurately than introverts. Apparently, extraverts were less influenced by gaze position than were introverts. Ellgring and von Cranach (1972) found that they could improve the receiver's accuracy by providing feedback, but that degree of improvement did not correlate with extraversion or visual acuity.

Buck, Savin, Miller, and Caul (1972) were interested in the relation between personality dimensions and performance for both the sender and the receiver in their study of facial expression. Senders viewed a series of slides. Five categories of slides were presented: sexual, maternal, scenic, unusual, and unpleasant. After each slide was presented, the sender described his/her own emotional response and rated the pleasantness/unpleasantness experienced while viewing the slide. Receivers watched a silent video tape of the sender's face, without being able to see the slides the sender was viewing. After each slide presentation, the receiver indicated the type of slide she/he thought the sender had seen and rated the degree of pleasantness the sender expressed. Receivers' extraversion scores on the Maudsley Personality Inventory were not found 
to be correlated with either the receivers' accuracy on the categorization task or with the degree of agreement between sender-receiver pairs on the pleasantness rating.

In 1972, Cartier included an extensive review of the 1iterature on nonverbal communication as part of her dissertation. The Relationship between Introversion-Extraversion and the Ability to Assess Nonverbal Behavior Patterns. She reported that " no studies were found that investigated the relationship between the introverted and extraverted personality dimensions and nonverbal processes"(p. 13). She was interested in individual differences in counselor effectiveness that might result from differing ability to interpret nonverbal behavior. She showed a film of a counseling session to counselors-in-training and asked them to assess which nonverbal cues had appeared in the film, using a Semantic Differential Rating Scale she had developed. The scale listed 40 behaviors, such as "shrugs shoulders" or "straightens up in chair." Three bi-polar adjectives, such as "relaxed-tense" or "active-passive," were provided for each behavior (pp. 100-106). Subjects' scores on the rating scale were compared with their extraversion scores on the Maudsley Personality Inventory. Contrary to Cartier's hypothesis that subjects scoring high on introversion would score higher on the rating task than would the extraverts, there was no difference between the groups.

Genther and Moughan (1977) were interested in the other side of the desk: They hypothesized that "...helpees of different personality types respond differently to the same helper behavior" (p. 144). To test this, they asked subjects to spend two minutes describing a dream to a confederate who listened silently. The confederate was instructed to maintain an upright sitting position with half the subjects; with the 
other half, he was to lean forward in his chair. (The authors did not report the sex of the confederate or the subjects.) Following their two-minute session, subjects were asked to rate the confederate on a rating scale of nine bipolar adjectives, such as understanding-not understanding and threatening-nonthreatening. Ratings were compared with the subjects' score on the extraversion scale of the Eysenck Personality Questionnaire. The hypothesis that introverts, who are typically described as reserved, would rate the listener who leaned forward more negatively was not supported. The only significant difference found among the subjects was that extraverts rated the listener who sat upright as more threatening than did introverts.

In 1979, Rosentha1, Ha11, DiMatteo, Rogers, and Archer summarized the results of eight years of research using the Profile of Nonverbal Sensitivity (PONS), a standardized measure of ability to decode nonverbal cues. (The PONS is described in the methods section below.) A high PONS score indicates a high degree of accuracy on this decoding task. Their results included evidence of sex differences, age differences, and cross cultural differences in decoding ability, and of cognitive and psychosocial correlates with individual difference in decoding ability (pp. 365-370). In summarizing the results of studies correlating PONS performance with several standard tests of personality, they reported that:

Subjects scoring higher on the PONS total also scored as better adjusted, more interpersonally democratic and encouraging, less dogmatic, more extraverted, more likely to volunteer for and appear for behavioral research, more popular, and more interpersonally sensitive as judged by acquaintances, clients, spouses, or supervisors. (pp. 369-370)

However, a more detailed look at the three studies reported by 
Rosenthal, Hal1, DiMatteo, Rogers, and Archer (1979,pp. 261-262), in which extraversion-introversion scores were correlated with PONS performance, revealed a less clear cut relationship than the summary would indicate. Two of the three studies used students in the helping professions as subjects, as did Cartier in her doctoral research--in Rosenthal et al. the subjects were students of dance therapy. For both samples of dance therapists, subjects' introversion scores on the Myers-Briggs Type Indicator correlated with PONS performance: Extraverts scored higher than introverts on all but one channel. The subjects in the third study were industrial personnel managers who rated themselves on a nine-point scale of introversion. For this group, introverts scored higher than extraverts on all channels except one, a very different result from the first two studies. The subjects in the third study were also given the stillphoto version of the PONS. On the still-photo version, extraverts scored higher than introverts on most channels, a result in the same direction as the results for the first two groups who were given only the standard version of the PONS. Rosenthal and his colleagues could suggest no explanation for this result. They concluded the discussion with the statement that "A good deal of research is needed before we can say much about the nature of the relationship between introversion and sensitivity to nonverbal cues" (p. 262). Separate subscores can be derived from the PONS for sensitivity to positive or negative nonverbal cues, but no research has been reported on possible introvert-extravert differences to the two kinds of cues.

Of the studies reported here, only Rosenthal and his colleagues used the Myers-Briggs Type Indicator (MBTI), which is based on Jungian theory of personality types, as a measure of extraversion-introversion. 
Ellgring and von Cranach used the Brengelmanns' Fragebögen der Extraversion. The remaining studies used the $E$ scale from either the Eysenck Personality Questionnaire (EPQ) or its earlier form, the Maudsley Personality Inventory (MPI) as their measure of extraversion. The comparability of studies using disparate measures of extraversion-introversion is open to question. In regard to the EPQ and the MPI, Eysenck and Eysenck (1975) state:

The $E$ [extraversion] and $N$ [neuroticism] scales of the present questionnaire [EPQ] are so similar to the corresponding scales of the other questionnaires that whatever has been discovered about correlates of $E$ and $N$ with the use of the older scales must be assumed to apply with equal force to the new scales. (p. 3) However, some critics have questioned the Eysencks' contention on this point. Block (1978) notes that "the items carried over to the EPQ E scale or written anew emphasize primarily the sociability component and de-emphasize the implusivity component of former E scales" (p. 806). Scores on the EPQ E scale and the Myers-Briggs Type Indicator have been found to be positively correlated (Steele \& Kelly, 1976; Wakefield, Sasek, Brubaker, \& Friedman, 1976). A more detailed discussion of the comparability of the EPQ and the MBTI, as well as the larger question of the relation between Jungian type theory and Eysenck's hypothesized personality dimensions, is included in Appendix $A$.

The majority of the studies reported here involved nonverbal cues that varied along some dimension. Argyle et al. (1969) asked their subjects to distinguish between inferiority and neutrality. Buck et al. (1972) asked receivers to rate degree of pleasantness senders expressed. Genther and Moughan (1977), and Cartier (1972) had their subjects' respond to lists of bi-polar adjectives concerning qualitative aspects of the cues they perceived. Rosentha1, Ha11, DiMatteo, Rogers, and Archer 
(1979) used a technique that would have allowed them to differentiate sensitivity to different affect but choose to report only on overall accuracy. Ellgring (1970), von Cranach (1971), and Ellgring and von Cranach (1972) were not concerned about the expressive content of the cues being detected. Only Genther and Moughan reported finding an extravert-introvert difference on these dimensions; extraverts were found to be more likely to perceive threat.

The research reviewed here does not present any clear picture of a relationship between extraversion-introversion and decoding skill. Von Cranach (1971) found that under some conditions extraverts are more accurate in judging the direction of another's gaze, while under other conditions, introverts are more accurate. Genther and Moughan (1977) found that introverts and extraverts differ in their preception of one body posture but not another. Rosentha1, Ha11, DiMatteo, Rogers and Archer (1979) reported that for some groups of subjects, extraverts are more accurate at decoding nonverbal behavior, but that this result is not always found. Argyle et a1. (1969), Buck et a1. (1972), and Cartier (1972) reported no difference between extraverts and introverts on a variety of decoding tasks.

\section{EXTRAVERSION-INTROVERSION AND THE FEAR-FRUSTRATION HYPOTHESIS}

Summarizing their extensive research on sensitivity to nonverbal communication, Rosenthal, Ha11, DiMatteo, Rogers, and Archer (1979) concluded:

Despite the large amount of research we have done, we know little about factors that directly affect nonverbal sensitivity. Why do people differ in their abilities to "read" various channels and kinds of affect?... Such determinants could be genetic, physiological, or psychological. (p. 376) 
Eysenck $(1970,1973)$ has developed a theory of human behavior that incorporates all three levels-- psychological, physiological, and genetic. He postulates three basic dimensions of personality: extraversion-introversion, neuroticism-normality, and psychoticism-normality. Eysenck's theory is developed from and supported by a wide range of data, including clinical observation; performance on standardized psychological inventories like the Eysenck Personality Questionnaire; performance on experimental tasks involving motor movement, conditioning, and vigilance; and measures of brain activity and behavioral change following administration of drugs or surgery affecting the central nervous system.

Extraversion-introversion is a continuum. Individuals at the extraverted end of the scale are observed to be easygoing, gregarious, impulsive, and attracted to novel and exciting stimuli, while introverts are withdrawn, quiet, plan ahead, and generally avoid intense stimulation. Eysenck postulates that these differences in observable behavior stem from differences in brain activity that may be genetically acquired. These differences are centered in the Ascending Reticular Activating System (ARAS). The ARAS has a dual function: it is responsible for cortical arousal, and it is part of the feedback system that inhibits excitability. Eysenck postulates that at moderate levels of stimulus intensity, introverts experience higher levels of ARAS arousal than do extraverts. As a result, extraverts are "stimulus hungry"; they need and seek a higher level of stimulation to reach an optimal level of ARAS excitation, while introverts tend to be "stimulus avoidant" because the intense ARAS excitation experienced with higher stimulation exceeds comfortable levels. Furthermore, Eysenck postulates that the inhibitory function of the ARAS is stronger in extraverts than in introverts. This 
inhibitory function results in more rapid extinction of conditioned responses in extraverts than introverts when a conditioned stimulus is presented repeatedly in the absense of the unconditioned stimulus. The greater ARAS excitation experienced by introverts to unconditioned stimuli results in greater physiological responsitivity and more rapid acquisition of conditioned responses. Eysenck concludes that introverts are more "conditionable" than extraverts. He makes a theoretical leap from studies of classical conditioning to human socialization, speculating that because introverts are more conditionable, they are, therefore, more readily socialized, resulting in more conservative and conventional behavior toward others (Monte, 1977).

Gray $(1971,1972)$ proposed a revision to Eysenck's theory of extraversion-introversion. Gray's theory, which he calls the fear-frustration hypothesis, emphasizes susceptibility to punishment and nonreward, rather than general conditionability, as the salient difference between introverts and extraverts. Gray argues for the face validity of his hypothesis by pointing to Eysenck's own research on the different forms neuros is takes in extraverts and introverts. Neurotic extraverts often exhibit psychopathic behavior such as stealing and sexual abuse, indicating a tendency to seek reward without regard to possible punishment, and recidivism, suggesting a relative insensitivity to the effects of punishment. Neurotic introverts suffer more frequently from phobias, obsessions or acute anxiety states, suggesting exaggerated fear of punishing consequences, or from reactive depression, indicating extreme sensitivity to the frustrative effects of nonreward.

Gray contends that the same difference in susceptibility to punishment and nonreward can be seen in less exaggerated form in normal intro- 
verts and extraverts. He agrees with Eysenck's view that introverts are more highly socialized than extraverts. However, after reviewing data from laboratory conditioning experiments and physiological studies that do not seem to be adequately explained by Eysenck's theory, Gray rejects Eysenck's contention that introverts' greater degree of socialization is due to their being more easily conditioned in general. Instead, pointing to Eysenck's own definition of conscience as "a cluster of classically conditioned fear reactions" (Gray, 1972, p. 197), Gray proposes that it is due to greater susceptibility to such conditioned fear responses. He describes the way in which this takes place:

...Any stimulus, if it is sufficiently intense, may act as a punishment....As any stimulus is increased in intensity, the point at which it becomes punishing will be reached sooner, the more highly aroused the individual, i.e. ...the more introverted he is.... The greater susceptibility to punishment of the introvert may be derived from the same fundamental substrate of introversion-extraversion postulated by Eysenck: the introvert is more highly aroused than the extravert and is therefore more susceptible to punishment. (1972, p. 199)

Both Gray and Eysenck are committed to the idea that there is a physiological substrate underlying human behavior, and that an understanding of physiological functioning will illumine behavioral questions. The physiological side to Gray's proposed revision of the theory of extraversion-introversion is based on extensive experimentation on the effect of sodium amobarbital on animal behavior, conducted by N.E. Miller and others (Gray, 1972,pp. 183-185). It was found that amobarbital reduces the behavioral effects of punishment in approach-avoidance situations, without reducing the effect of reward in simple approach learning. The drug also reduces the behavioral effects of frustrative nonreward during extinction. This supports the idea that there are different physiological mechanisms governing behavior under different 
reinforcement contingencies. Further support is found in data on the behavioral effects of specifically located brain lesions and of electrical stimulation to specific areas of the brain. Based on all this information, Gray (1972) proposes that "...it is activity in this frontal cortex--medial septal area--hippocampal system which determines the degree of introversion: the more sensitive or active this system is, the more introverted will the individual be" (p. 190).

Thus, Gray considers a more extensive area of the brain to be included in the physiological system underlying degree of introversion than does Eysenck, who locates it in the ARAS alone. This extrapolation to human behavior from research done with rats is highly speculative. However, he has support in the field. Buck (1979) reviews additional research on intracranial brain stimulation, left-right cerebral lateralization, and the activity of endogenous morphine-like agents, and concludes the results complement Gray's proposal.

Gray (1972) concludes the discussion of his fear-frustration hypothesis with the statement that:

...The modified theory of introversion proposed has the same overall structure as Eysenck's original theory, although there are important differences in the detailed predictions which can be derived. (p. 201)

\section{PURPOSE OF THIS STUDY}

The fear-frustration hypothesis states that "...Relative to extraverts, introverts are relatively more susceptible to punishment and frustrative nonreward..." (Gray, 1972, p. 263). Based on this hypothesis, I predict that introverts are more sensitive to negative nonverbal cues than are extraverts. I will test this prediction by correlating subjects' scores on the Eysenck Personality Questionnaire E scale with their 
performance on the Profile of Nonverbal Sensitivity (PONS). I predict that introverts' PONS subscore for sensitivity to negative cues will be higher than their subscore for sensitivity to positive cues, and that the difference between these two subscores will be greater for introverts than for extraverts. 


\title{
SECTION III
}

\author{
METHODS
}

SUBJECTS

Students in two 300-level psychology night classes were asked to participate in this study. Responses were obtained from 88 of the students. Demographic data were not gathered, but it was observed that a number of the class members were international students from the Middle East and Southeast Asia, and that some of the students were older than the general undergraduate population.

\section{PROCEDURE}

With permission of the instructor, the researcher attended a regularly scheduled class session. The researcher explained to the students that they were being requested to volunteer for an experiment studying the relationship between personality traits and accuracy in receiving nonverbal communication. The experimental procedure was described and an informed consent form distributed, to be signed by those who choose to volunteer as subjects. (A copy of the consent form is included in Appendix B. It follows the model provided by the PSU Human Subjects Research Review Committee.)

Test booklets and answer sheets for the Eysenck Personality Questionnaire (EPQ) and the Profile of Nonverbal Sensitivity (PONS) were distributed to all who chose to participate. Subjects were asked to 
check the code number at the top of their copies of the EPQ test booklet and the PONS answer sheet so that the results could be matched later for data analysis. Subjects were asked to record their sex in the appropriate place on the test booklet and answer sheet, but to omit the other personal information requested there, such as name and occupation.

The standard instructions for the EPQ were read. After 15 minutes, or as soon as the last subject had completed the EPQ, the standard instructions for the PONS were read. Subjects were encouraged to remain attentive and to complete all items on the answer sheet. The 45-minute PONS film was projected on a screen at the front of the classroom.

At the end of the film, the answer sheets, test booklets, and consent forms were collected. Subjects were thanked for their participation. The researcher returned to each class several weeks later to discuss the results and answer questions. Individual scores, identified by code number only, were available to those subjects who wished to see them.

\section{INSTRUMENTS}

\section{Eysenck Personality Questionnaire}

The Eysenck Personality Questionnaire (Eysenck \& Eysenck, 1975) is a 90-item forced choice questionnaire. It is essentially self-administering and can be completed in 15 to 20 minutes. It measures three dimensions of temperament, which are considered to be orthogonally independent: Extraversion-Introversion (E); Neuroticism-Stability (N); and Psychoticism-Normality (P). There is also a Lie scale $(L)$ to detect falsified or distorted responding. Of the 90 items on the Eysenck Personality Questionnaire (EPQ), 21 measure E, 23 measure $N, 25$ measure 
$P$, and 21 measure $L$. The $N$ and $P$ scales are not relevent to the hypothesis being tested in this study, and so were not scored.

The EPQ is the latest personality instrument to be developed by the Eysencks. This line of work began in 1952 with the Maudsley Medical Questionnaire, a measure of N. The Maudsley Personality Inventory, developed in 1962, included scales for $\mathrm{N}$ and $\mathrm{E}$. The Eysenck Personality Inventory appeared in 1968. It included the $L$ scale as well as several other methodological improvements. Eysenck and Eysenck (1975) have introduced an additional variable $P$ in the $E P Q$.

Profile of Nonverbal Sensitivity (PONS)

The Profile of Nonverbal Sensitivity (Rosenthal, Hall, Archer, Dimatteo, \& Rogers, 1979) consists of a 45-minute black and white $16-\mathrm{mm}$ motion picture with sound track (also available on videotape) and a multiple-choice answer sheet. The film is composed of 220 numbered segments, each two seconds in length, corresponding to the 220 items on the answer sheet.

The film segments were derived from longer film clips of a 24-yearold female Caucasian American graduate student portraying 20 different scenes, each of which contains different emotional content. The scenes range from ordering food in a restaurant to confronting a sexual rival. Transcripts of the 20 scenes are provided by Rosenthal, Ha11, DiMatteo, Rogers, and Archer (1979, pp. 47-48). Ten of the scenes express positive affect; ten, negative. Ten express dominance; ten, submission, in a twoby-two matrix design (see Table I). 
TABLE I

\section{CLASSIFICATION OF THE 20 PONS SCENES \\ ON THE DIMENSIONS OF \\ POSITIVITY AND DOMINANCE}

DOMINANCE

Low

(Submissive)

High

$P$
0
S
$I$
$T$
$I$
$V$
$I$
$T$
$Y$

I High

(Positive)

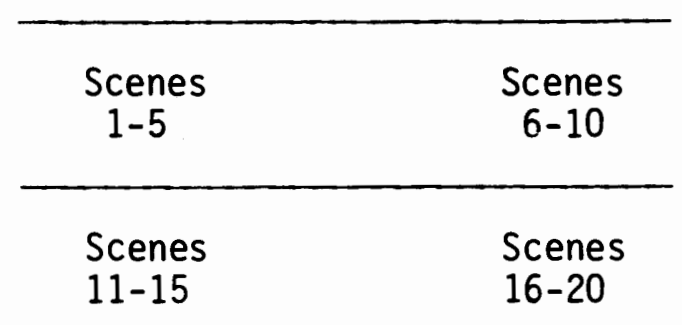

There are 11 segments in the PONS from each of the 20 scenes, for a total of 220 segments.

The segments of the PONS are of 11 different types, referred to as channels. The first five are labeled "pure" channels; the remaining six are "mixed" channels. The content of the 11 channels is listed in Table II.

\section{TABLE II}

THE ELEVEN PONS CHANNELS

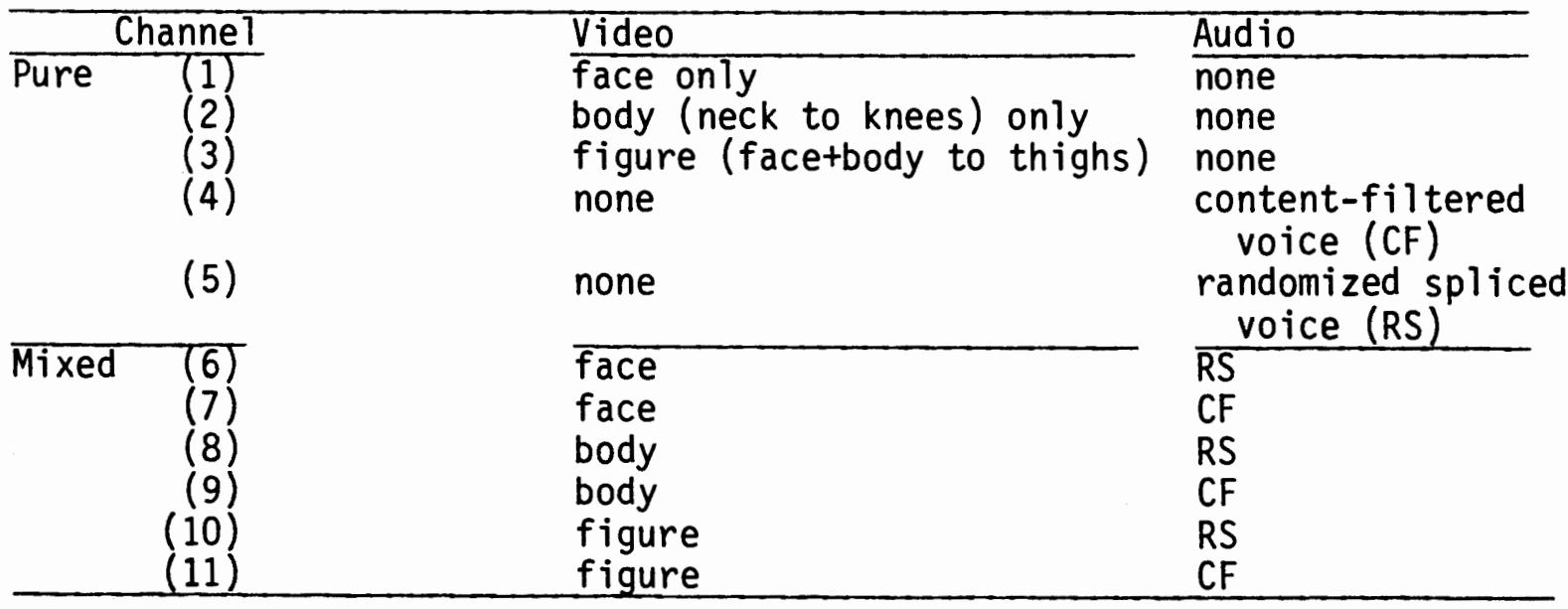

Content-filtered voice (CF) and randomized spliced voice (RS) re- 
quire further explanation. Both are means for studying the other communicative components of human speech apart from the verbal message being conveyed.

Rosenthal and colleagues describe the electronic content-filtering process as follows:

It removes selected bands of frequencies and clips the audio signal so that the voice sounds muffled and slightly distorted. By carefully adjusting the various controls, the intonation, rhythm, tempo, and loudness of the voice can be kept the same, while speech intelligibility is lost. (Rosenthal, Hall, DiMatteo, Rogers, \& Archer, 1979 , p. 25).

Randomized splicing is just what the name implies: the audio tape is physically cut into very short pieces which are spliced back together again in random order. The voice sounds "natural" but words can no longer be understood.

In the PONS, each of the 11 segments selected from each scene is presented in a different channel. Since there are 20 different scenes, the test taker is exposed to each channel 20 times. Figure 3 shows in schematic form how the 220 PONS segments are distributed.

TABLE II I

DISTRIBUTION OF THE 220 PONS SEGMENTS AMONG THE TWENTY SCENES AND ELEVEN CHANNELS

CHANNELS

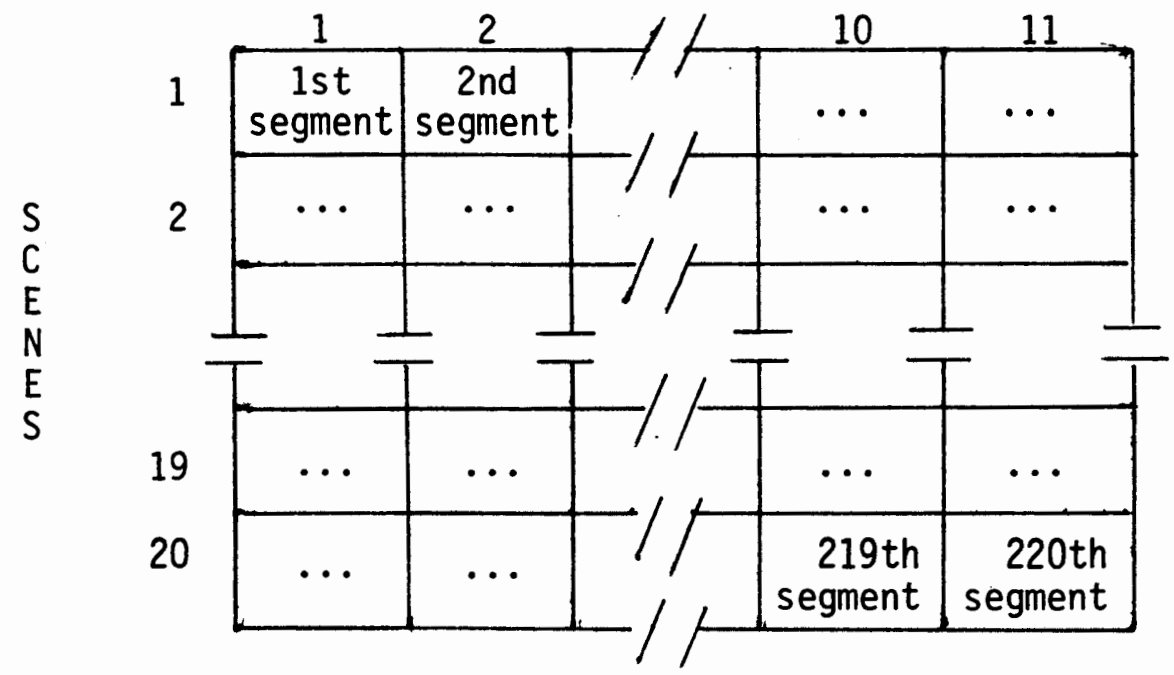


In the final version of the PONS, the 220 segments are assembled in random order. Nine seconds of film were inserted between each twosecond segment. The insert consists of five seconds of blank film, a two-second presentation of the item number (1-220), and another two seconds of blank film, followed by the segment itself.

The answer sheet consists of 220 multiple-choice items. The choices are selected from twenty phrases, each identifying the situation portrayed in one of the 20 segments (e.g., "helping a customer," "threatening someone," etc). Each item consists of two choices-- a correct choice, identifying the scene in the film segment just viewed, and an incorrect one, randomly selected from the remaining nineteen scenes. During the five second pause after each segment, the subject marks his/ her choice for that item on the answer sheet.

Each subject receives a score for total number of correct items on the PONS. In addition, subscores can be derived for accuracy on each of the 11 channels and for each of the four types of scenes (positive-dominant, positive-submissive, negative-dominant, negative-submissive), resulting in a profile of sensitivity for each subject. 


\section{SECTION IV}

\section{RESULTS}

Of the 88 subjects who participated, 23 could not be used in this study, because their responses were incomplete. The remaining 65 included 32 females and 33 males. Two of these were dropped for reasons discussed below. Thus, the final sample of 63 included 32 females and 31 males.

\section{EXTRAVERSION-INTROVERSION}

The female subjects' scores on the E scale of the Eysenck Personality Inventory ranged from a low of 2 (very introverted) to a high of 21 (very extraverted), out of a possible 23 points. The mean E score for females was 13.78 and the median, 13.5, with a standard deviation of 5.31. The male subjects' EPI E scores were distributed over a narrower range, 5 - 19. For males, the mean was 13.67, median, 14.83, and the standard deviation, 3.92. These results are displayed in Table I, along with the British population norms, which are taken from the EPI Manual (Eysenck \& Eysenck, 1975). The differences between the sample means and the norm group means were not significant.

The median E score for each sex was used as a cutting point to divide the sample into the following four groups: Introverted Females $(N=16)$, Extraverted Females $(N=16)$, Introverted Males $(N=16)$, and Extraverted Males $(N=15)$. The two males whose $E$ scores fell on the 
TABLE IV

SCORES ON THE EYSENCK PERSONALITY

INVENTORY E SCALE

$\begin{array}{lrrrrrr}\text { Sex } & \text { Range } & \text { Mean } & \text { Median } & \text { S.D. } & \text { Mean } & \text { G.D. } \\ \text { Female } & 2-21 & 13.78 & 13.50 & 5.31 & 12.60 & 4.83 \\ \text { Male } & 5-19 & 13.67 & 14.83 & 3.92 & 13.19 & 4.91\end{array}$

median were dropped. Because the median was used to divide each group into introverts and extraverts, the difference in medians for males and females was checked for statistical significance. The results of the Mann-Whitney $\underline{U}$ test were nonsignificant.

\section{NONVERBAL SENSITIVITY}

Males were significantly less accurate (see Table VII) and more variable ( $F$ test, $\mathrm{p}<.002$ ), than females in identifying the nonverbal scenes portrayed in the Profile of Nonverbal Sensitivity. Results for the two sexes, out of a maximum possible score of 220 , are displayed in Table V. The norms are from Rosenthal, Ha11, DiMatteo, Rogers \& Archer (1979). Differences between the sample means and the norm group means were not statistically significant.

\section{TABLE V}

TOTAL SCORES ON THE PROFILE OF NONVERBAL SENSITIVITY

$\begin{array}{lccccrr}\text { Sex } & \text { Range } & \text { Mean } & \text { Median } & \text { S.D. } & \frac{\text { Norm }}{\text { Mean }} & \text { Group } \\ \text { Female } & 160-192 & 176.97 & 177.5 & 7.53 & 172.19 & 11.22 \\ \text { Male } & 127-187 & 170.73 & 173.83 & 12.49 & 166.18 & 13.45\end{array}$


The total score on the PONS (PONS total) can be divided into two subscores: one for accuracy on the 110 test items presenting positive affect PONSt), and one for the 110 items presenting negative affect (PONS-). Almost all subjects were more accurate on PONS- than on PONSt. When the PONS+ score was subtracted from the PONS- score, the difference (PONS $\triangle$ ) was positive in 59 out of 65 cases. This is significant at the $\mathrm{p}<.0003$ level, using the binomial test.

The PONSt and PONS- scores for the four groups--introverted males and females, and extraverted males and females--are displayed Table VI.

\section{TABLE VI}

POSITIVE AND NEGATIVE SUBSCORES ON THE PROFILE

OF NONVERBAL SENSITIVITY

\begin{tabular}{|c|c|c|c|c|c|c|}
\hline \multirow[b]{2}{*}{ Group } & \multicolumn{3}{|c|}{ PONS+ } & \multicolumn{3}{|c|}{ PONS- } \\
\hline & Range & Mean & S.D. & Range & Mean & S.D. \\
\hline IF & $76-93$ & 83.44 & 5.39 & $89-100$ & 94.50 & 3.83 \\
\hline IM & $64-91$ & 79.19 & 6.68 & $63-99$ & 88.06 & 8.54 \\
\hline$E F$ & $77-98$ & 84.63 & 5.32 & $82-103$ & 92.25 & 6.12 \\
\hline EM & $69-90$ & 82.27 & 6.43 & $83-100$ & 93.20 & 5.70 \\
\hline & & $\begin{array}{l}\text { Introv } \\
\text { Extrav }\end{array}$ & & $\begin{array}{l}\text { Female } \\
\text { Male }\end{array}$ & & \\
\hline
\end{tabular}

An analysis of variance on the three factors (sex, extraversionintroversion, PONS \pm ) revealed that the within-subjects difference between PONS+ and PONS- was significant at the $\mathrm{p}<.001$ level, and that the between subjects sex difference was significant also, at the $\mathrm{p}<.025$ lever. The between subjects variance for extraversion-introversion was not significant. The within-subjects interaction effects of PONS \pm and extraversion-introversion, and of PONS \pm and sex, were not significant. 
TABLE VII

ANALYSIS OF VARIANCE ON THREE FACTORS:

EXTRAVERSION-INTROVERSION, SEX, PONS+

\begin{tabular}{|c|c|c|c|c|c|}
\hline Source & SS & $d f$ & $\mathrm{~ms}$ & $F$ & $p$ \\
\hline 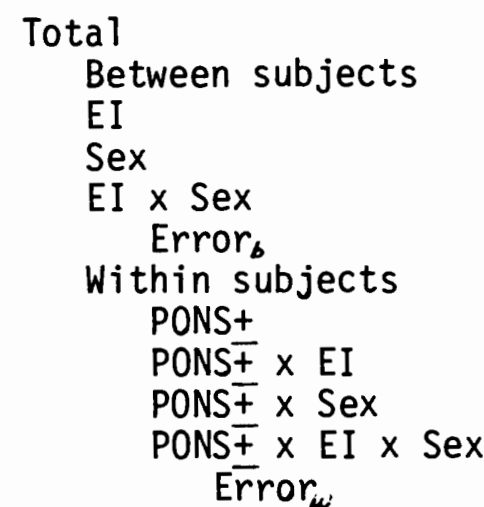 & $\begin{array}{r}7974.80 \\
3778.30 \\
102.02 \\
300.73 \\
163.84 \\
3211.71 \\
4196.50 \\
2904.96 \\
4.35 \\
2.19 \\
59.31 \\
1225.69\end{array}$ & $\begin{array}{r}125 \\
62 \\
1 \\
1 \\
1 \\
59 \\
63 \\
1 \\
1 \\
1 \\
1 \\
59\end{array}$ & $\begin{array}{c}-- \\
-- \\
102.02 \\
300.73 \\
163.84 \\
54.44 \\
-- \\
2904.96 \\
4.35 \\
2.19 \\
59.31 \\
20.77\end{array}$ & $\begin{array}{c}-- \\
-- \\
1.87 \\
5.52 \\
3.01 \\
-- \\
-- \\
139.86 \\
.21 \\
.11 \\
2.86 \\
--\end{array}$ & $\begin{array}{l}-- \\
<- \\
<.02 \\
<.02 \\
-- \\
<- \\
-.001 \\
--- \\
<.1\end{array}$ \\
\hline
\end{tabular}

Two interaction effects approached significance, with $.1>p>05$. They were the between subjects interaction of extraversion-introversion and sex, and the three-way within subjects interaction of PONS \pm with extraversion-introversion and sex. When the means for each of the four groups are placed in rank order, as in Figure 1, it can be seen that in al1 conditions, introverted females are, as a group, more accurate than extraverted males, who, in turn, are more accurate than introverted males. The relative position of the extraverted females varies from highest on PONS+ to next lowest on PONS-. However, the analysis of variance reveals that this trend is not significant $(p>.05)$.

The last column of Figure 1 , PONS $\Delta$, shows the relative position of the four groups on the mean difference between PONS- score and PONSt. It suggests that introverted females are the most specialized in accurately identifying negative nonverbal cues, relative to their skill at detecting positive nonverbal cues, and that extraverted females are the 
Rank

PONS+ PONS total PONS- PONS $\triangle$

1

2

3

4

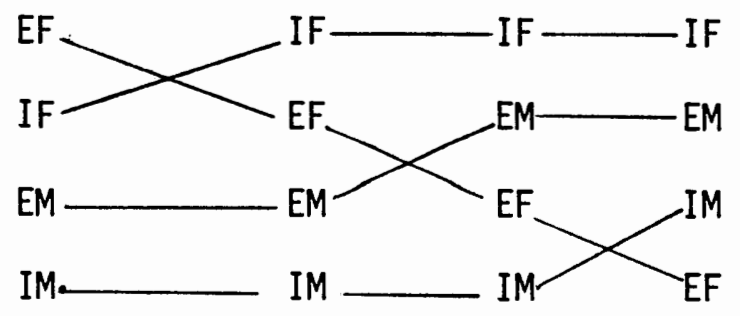

$$
\begin{aligned}
& \text { PONS total }=(\text { PONS }-)+(\text { PONS }+) \\
& \text { PONS } \triangle=\text { (PONS-) }-(\text { PONS }+) \\
& \begin{array}{ll}
I=\text { Introverted } & F=F \text { Female } \\
E=\text { Extraverted } & M=\text { Male }
\end{array}
\end{aligned}
$$

Figure 1. Rank ordering of group means for Profile of Nonverbal Sensitivity scores

least specialized. However, the Pearson product-moment correlations between $E$ score and PONS $\Delta$, which are displayed in Table VIII, are not significant for any of the groups. To be significant at the $\mathrm{p}<.05$ level, $\underline{r}$ must be $>.4973$ for $\underline{d f}=14$, and $\underline{r}>.5139$ for $\underline{d f}=13$.

\section{TABLE VIII}

CORRELATION BETWEEN E SCORE AND PONS $\triangle$

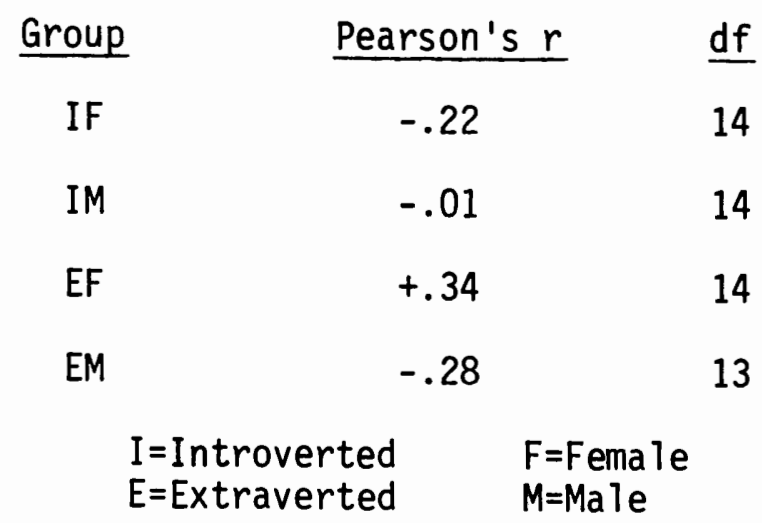

\section{RESPONSE BIAS}

PONS scores were examined for possible response bias. PONS test items can be grouped into four types: those items for which the correct 
and the incorrect responses are both positive $(+/+)$, those items for which the correct response is positive and the incorrect response is negative $(+/-)$, those items for which the correct response and the incorrect are both negative $(-/-)$, and those items for which the correct response is negative and the incorrect response is positive $(-/+)$.

of the 110 items for which the correct response is positive (PONS+), 52 are of the $+/+$ type, and 58 of the $+/$ - type. Of the 110 items for which the correct response is negative (PONS-), 42 are of the $-1-$ type and 68 are $-1+$.

The four types of test items can be viewed as belonging to one of two categories: the pure category, where the sign of both the correct and incorrect response alternatives are the same $(+/+,-/-)$; and the mixed category, where the signs of the two response alternatives differ $(+/-,-1+)$. The PONS includes 94 items in the pure category and 126 in the mixed. If subjects are not biased in favor of one response alternative $(+$ or - ), there should be a high correspondence between accuracy on pure test items and accuracy on mixed items. As a group, females answered correctly on $77 \%$ of the pure items and $83 \%$ of the mixed items. Males answered correctly on $78 \%$ of the pure items and $82 \%$ of the mixed items. The result of the test of the difference of two proportions was small, but statistically significant for each sex ( $p<.001)$. Therefore, response bias cannot be discounted as a factor influencing the PONS test results. 


\section{SECTION V}

\section{DISCUSSION}

The results do not support the hypothesis that introverts are more sensitive to negative nonverbal cues than are extraverts and that the difference between negative and positive PONS subscores would be greater for introverts than for extraverts. As reported above, there was no significant interaction effect between PONS \pm and extraversion-introversion, and there was no significant correlation between PONS $\Delta$ and $E$ score. The prediction that these measures would be significant was based on Gray's (1979) fear-frustration hypothesis which states that introverts are more susceptible than extraverts to the effects of punishment and nonreward. The alternative hypothesis, that introverts would be more sensitive to nonverbal communication in general, was not supported either. The alternative hypothesis is based on Eysenck's $(1970,1973)$ theory of extraversion-introversion, that states that introverts are more conditionable than extraverts, because they experience higher levels of arousal than do extraverts to moderate stimuli, both positive and negative.

The finding that the three-way interaction of sex $X$ PONS $\pm X$ extraversion-introversion did approach statistical significance suggests that the extraversion-introversion variable may yet be found to be of predictive value in measures of decoding skill, but only in combination with other factors. Decoding of nonverbal communication is a complex social skill that does not lend itself to a simple test between these alternative 
trait theories derived in part from physiological and classical conditioning data.

The results did support the findings of Hall (1979) and of Rosenthal and DePaul (1979) that females will be found to be more sensitive to all nonverbal cues than are males. This study found both sexes to be somewhat more sensitive to negative nonverbal than positive, as did Rosenthal, Hal1, DiMatteo, Rogers and Archer (1979). Male responses were found to be more variable than female responses, a factor not reported by Rosenthal and his colleagues.

Rosenthal, Ha11, DiMatteo, Rogers and Archer (1979) stated that "there appeared to be little evidence for appreciable bias in the [PONS] answer sheet" ( $p .37)$. The results of the comparison of accuracy on the $+/+,+/-,-/-$ and $-/+$ test $i$ tems indicate that response bias cannot be discounted.

\section{CONCLUSION}

It is not possible to predict the relationship between sensitivity to nonverbal communication and extraversion-introversion from either Gray's fear-frustration hypothesis or Eysenck's general conditionability hypothesis.

\section{IMPLICATIONS FOR FURTHER RESEARCH}

In his review of research on eyeblinks, Eysenck (1973) reported:

Our data show that it is possible to choose conditions which give results favouring introverted subjects or extraverted subjects; what is interesting and important is that these conditions could be formulated and stated on theoretical grounds, so that the experimental results serve to support and verify the theory. (p. 167) 
It is not yet clear what factors, if any, may influence the relative abilities of extraverts and introverts to decode nonverbal cues. The possibility of interaction between type of cues to be detected and extraversion-introversion merits further investigation. Specifically, the PONS subscores for the 11 channels, composed of combinations of face, body and audio cues, could be examined for interaction with extraversionintroversion.

Friedman (1979) has observed a shift in orientation in research on nonverbal communication away from motives and traits as explanatory constructs and toward the study of skills and abilities. He sees this trend not as supplanting trait theory, but as breathing fresh life into our concepts of traits. He proposes the idea that "nonverbal skills are the expressive counterparts of traits" (p. 13), raising empirical questions about nonverbal sending skill such as "Does an extravert become expressive, does a highly skilled sender become an extravert, or are the two concepts the same thing?" (p. 13). The relationship between the skill of nonverbal decoding and the trait extraversion-introversion, if it exists, remains to be clarified. 


\section{REFERENCE NOTE}

1. Rosenthal, R. Personal communication, December 2, 1980. 


\section{REFERENCE LIST}

Argyle, M., Salter, V., Nicholson, H., Williams, M., \& Burgess, P. La communication des attitudes d'inferiorite et de superiorité par signaux verbaux et non verbaux. Bulletin de Psychologie, $1969-70, \underline{23}, 540-548$.

Block, J. The Eysenck Personality Questionnaire. In 0.K. Buros (Ed.), The eighth mental measurements yearbook. Highland Park, N.J.: Gryphon Press, $197 \overline{8}$

Buck, R. Individual differences in nonverbal sending accuracy and electrodermal responding: The externalizing-internalizing dimension. In R. Rosenthal (Ed.), Skill in nonverbal communication: Individual differences. Cambridge, MA.: Oelgeschlager, Gunn \& Hain, 1979 .

Buck, R.W., Savin, V.J., Miller, R.E., \& Caul, W.F. Communication of affect through facial expressions in humans. Journal of Personality and Social Psychology, 1972, 23, 362-371.

Cartier, S.V.E. The relationship between introversion-extraversion and the ability to assess nonverbal behavior patterns (Doctoral dissertation, Boston University, 1972). Dissertation Abstracts International, 1972, 33, 1430A. (University Microfilms No. 72-25, 424)

Coan, R.W. The Myers-Briggs Type Indicator. In 0. K. Buros (Ed.), The eighth mental measurements yearbook. Highland Park, N.J.: Gryphon Press, 1978.

Darwin, C.R. The expression of emotions in man and animals. New York: Appleton, 1873.

Duncan, S., Jr. Nonverbal communication. Psychological Bulletin, 1969, 72, 118-137.

Ellgring, J.H. Die beurteilung des blicks auf punkte innerhalb des gesichtes. Zeitschrift fur Experimentelle und Angewandte Psychologie, $1970,17,600-607$. (Author's Englis summary, pp. 606607)

Ellgring, J.H., \& von Cranach, M. Process of learning in the recognition of eye-signals. European Journal of Social Psychology, 1972, 2 , 33-43. 
Eysenck, H.J. The structure of human personality (3rd ed.). London: Methuen, 1970 .

Eysenck, H.J. Eysenck on extraversion. London: Crosby Lockwood Staples, 1973.

Eysenck, H.J. \& Eysenck, S.B.G. Manual: Eysenck Personality Questionnaire. San Diego, CA.: EDITSTEducationaT and Industrial Testing Service, 1975.

Friedman, H.S. The concept of skill in nonverbal communication: Implications for understanding social interaction. In R. Rosenthal (Ed.), Skill in nonverbal communication: Individual differences. Cambridge, MA.: 0elgeschlager, Gunn \& Hain, 1979.

Genther, R.W., \& Moughan, J. Introverts' and extraverts' responses to nonverbal attending behavior. Journal of Counseling Psychology, $1977,24,144-146$.

Gray, J.A. Strength of the nervous system, introversion-extraversion, conditionability and arousal. In H.J. Eysenck (Ed.), Readings in extraversion-introversion (Vol. 1). New York: Wiley-Interscience, 1971.

Gray, J.A. The psychophysiological nature of introversion-extraversion: A modification of Eysenck's theory. In V.D. Nebylitsyn \& J.A. Gray (Eds.), Biological bases of individual behavior. New York: Academic Press, 1972.

Hall, J.A. Gender, gender-roles, and nonverbal communication skills. In R. Rosenthal (Ed.), Skill in nonverbal communication: Individual differences, Cambridge, MA.: Oelgeschlager, Gunn \& Hain, 1979.

Harper, R.G., Weins, A.N., \& Matarazzo, J.D. Nonverbal communication: The state of the art. New York: John Wiley \& Sons, 1978.

Mendolsohn, G.A. The Myers-Briggs Type Indicator. In 0. K. Buros (Ed.), The sixth mental measurements yearbook. Highland Park, N.J.: Gryphon Press, 1965.

Monte, C.F. Beneath the mask: An introduction to theories of personality. New York: Praeger, $197 \overline{7}$.

Morris, N.M., \& Udry, J.R. Pheromonal influences on human sexual behavior: An experimental search. Journal of Biosocial Science, 1978, 10, $147-157$.

Myers, I.B. Manual: The Myers-Briggs Type Indicator. Palo Alto, CA.: Consulting Psychologists Press, 1962 .

Rosenthal, R., \& DePaulo, B.M. Sex differences in accommodation in nonverbal communication. In $R$. Rosenthal (Ed.), Skill in nonverbal communication: Individual differences. Cambridge, $\overline{M A}$.: 0elgeschlager, Gunn \& Hain, 1979 . 
Rosentha1, R., Hal1, J.A., Archer, D., DiMatteo, M.R., \& Rogers, P.L. The PONS test manual: Profile of Nonverbal Sensitivity. New York: Irvington, 1979.

Rosentha1, R., Hall, J.A., DiMatteo, M.R., Rogers, P.L., \& Archer, D. Sensitivity to nonverbal communication. Baltimore: Johns Hopkins University Press, 1979.

Steele, R.S., \& Kelly, T.J. Eysenck Personality Questionnaire and Jungian Myers-Briggs Type Indicator correlation of extraversionintroversion. Journal of Consulting and Clinical Psychology, 1976, 44, 690-691.

Sundberg, N.D. The Myers-Briggs Type Indicator. In 0. K. Buros (Ed.), The sixth mental measurements yearbook. Highland Park, N.J.: Gryphon Press, 1965.

Von Cranach, M. The role of orienting behavior in human interaction. In A.H. Esser (Ed.), International symposium on the use of space by animals and men, Dallias, 1968. New York: Plenum Press, 1971.

Wakefield, J.A., Jr., Sasek, J., Brubaker, M.L., \& Friedman, A.F. Validity study of the Eysenck Personality Questionnaire. Psychological Reports, 1976, 39, 115-120.

Wiener, M., Devoe, S., Rubinow, S., \& Geller, J. Nonverbal behavior and nonverbal communication. Psychological Review, 1972, 7.9, 185-214. 


\section{APPENDIX A}

\section{EYSENCK AND JUNG}

Reported research on correlations between PONS scores and extraversion-introversion have used either the EI Index of the Myers-Briggs Type Indicator, or a simple nine-point scale of introversion (Rosenthal, Note 1; Rosenthal, Ha11, DiMatteo, Rogers, \& Archer, 1979). The thes is to be tested in this study is derived from the work of Gray (1971, 1972), who, in turn, has adapted Eysenck's concept of extraversion-introversion. Therefore, the Eysenck Personality Questionnaire E Scale has been chosen as the appropriate instrument for this research.

Scores on the MBTI EI Index and the EPQ E Scale have been found to be positively correlated (Steele \& Kelly, 1976; Wakefield, Sasek, Brubaker, \& Friedman, 1976). In reporting the results of correlation studies of the two scales, these researchers have revealed differing opinions about the theoretical relationship between the MBTI, which is derived from Jungian type theory (Myers, 1962), and the EPQ, which Eysenck developed. Steele and Kelly (1976) consider the high correlation to be surprising, being of the opinion that Jung and Eysenck "developed their concept of extraversion-introversion from radically different theoretical orientations" (p. 690). In contrast, Wakefield et al. (1976) state that the result is "exactly as expected" (p. 119), because the two instruments share "the same theoretical background" (p. 115). There is no dispute about the derivation of the MBTI from Jungian type theory, though some have questioned how successfully it was accomplished (Coan, 1978, p. 973- 
975; Mende1sohn, 1965,pp. 321-322; Sundberg, 1965,pp.322-325). Eysenck's theoretical relationship to Jung and hence to the MBTI is more problematical. Monte (1977) writes:

The concepts of introversion-extraversion were, in most psychologists' minds, associated with Carl Jung's typology. But aside from Jung's basic premise of an association between psychasthenia ....and introversion, and between extraversion and hysteria, Eysenck accepted none of Jung's formulation. (p. 597)

Eysenck's own view of his relationship to Jung's ideas can be deduced from his major review of personality theory and research, The Structure of Human Personality (Eysenck, 1970). Eysenck begins by enumerating the criticisms that have been advanced in regard to trait theories of personality and proposes that the concept of type resolves these objections. He goes on to introduce Jung and Kretschmer as the theorists "whose concepts have been most influential in creating modern typology..." (p. 11).

Eysenck (1970) defines type as a pattern of intercorrelations among observable traits, noting that "...this model of personality organization derives directly from the writings of psychologists like Jung, Kretschmer and Allport..." (p. 14). While these individuals made little or no use of psychometrics, deducing their hypothetical models from "clinical experience and acute psychological insight," they have been found to fit "almost completely with the statistical models elaborated by factor analysts" (p. 14).

Eysenck interprets Jung in a way which emphasizes the similarities with his own theoretical position. For example, Eysenck (1970) argues that it is a "widespread misconception" that Jung considered types to be discontinuous ( $p, 11)$. Eysenck's position that extraversion-introversion is a continuum along which individuals are distributed is reflected in the scoring of the Eysenck Personality Questionnaire E Scale. A low E 
score indicates introversion; a high $\mathrm{E}$ score, extraversion. On the other hand, Myers, a traditional Jungian, assumes that the types are bimodal and discontinuous. The EI Index of the Myers-Briggs Type Indicator is scored as two discrete variables: the test taker receives either an $E$ score or an I score. Myers (1962) discusses this at length, noting that "The construction of an instrument to identify the Jungian types involves one unique problem, namely the location of the division-point between one type and another" (p. 89). Myers' critics dispute her evidence for bimodality in the score distributions, but don't question the theoretical basis for seeking it (Mendelsohn, 1965).

Eysenck's individualistic reading of Jung can also be seen in his statement (1970) that a neuroticism factor is implicit in Jung's theory, "although Jung never formally elaborated this part of his hypothesis..." (p. 24). In contrast, Eysenck has little interest in many of the theoretical aspects that Jung did choose to elaborate upon: Eysenck (1970) remarks that he will not discuss "Jung's amplification of his theories in terms of the four functions of feeling, thinking, sensation, and intuition," because "little is gained by the discussion of refinements when the major structures [extraversion and neuroticism] are in doubt" (p. 26). The identification of extraversion and neuroticism as the major personality structures is Eysenck's, rather than Jung's. Similarly, Eysenck (1970) cuts short his description of the traits Jung considered to be characteristic of the extravert with the comment that "our main interest will be in the empirical verification of Jung's conception, rather than in its detailed statement" (p. 24). The conclusion Eysenck reached on this point is reflected in the manual for the EPQ (Eysenck, 1975): "Descriptively, the factorial studies of $E$ have resulted in a picture 
which may resemble, but is certainly not identical with that given by Jung..." (p. 5).

Another point where Eysenck (1970) finds research at odds with Jungian theory is "the proposition that psychotic and neurotic disorders 7ie along one and the same continuum of 'abnormality'" (p. 28), a view held explicitly by Freud and Kretschmer, and an underlaying assumption in Jung's work. Eysenck

comes to the conclusion that experimental findings are solidly opposed to the hypothesis of one single dimension of abnormality, and that two such dimensions, orthogonal to each other and dealing respectively with neurotic and psychotic disorders, are required. (pp. 29-30)

Eysenck (1970) lists Jung among those whose theories "have influenced and in large measure determined the empirical studies described" in his review of his own and other typologists' research on personality structure (p. 17). The three aspects of Jungian theory that seem to be most solidly supported by research results he cites are the centrality of extraversion-introversion as an organizing principle in personality structure (pp. 183-184); the independence of neuroticism and introversion, a point that is "especially stressed by Jung" (p. 25), contrary to Freud, whose views are not supported (pp.178-179); and Jung's insight that "the extravert in cases of neurotic breakdown is predisposed to hysteria, the introvert to psychasthenia," (p. 24), a tendency also revealed by factor analysis (pp.189-190). 

hereby agree to serve as a subject in a research project on extraversion-introversion and sensitivity to nonverbal communication, conducted by Virginia Seiser, under the supervision of Dr. Chadwick Karr.

I understand that the study involves taking two standardized tests, the Eysenck Personality Questionnaire, and the Profile of Nonverbal Sensitivity.

It has been explained to me that the purpose of this study is to learn more about the relationship between the personality dimension of extraversion-introversion and individual differences in skill at interpreting nonverbal cues.

I may not receive any direct benefit from participation in this study, but my participation may help to increase knowledge which may benefit others in the future.

Virginia Seiser has offered to answer any questions I may have about the study. I have been assured that all information I give will be kept confidential and that the identity of all subjects will remain anonymous.

I understand that I am free to withdraw from participation in this study at any time without jeopardizing my relationship with Portland State University or my grade in this course.

I have read and understand the foregoing information. DATE SIGNATURE

If you experience problems that are the result of your participation in this study, please contact Victor Dahl, Office of Graduate Studies and Research, 105 Neuberger Hal1, PSU, 229-3423. 